\section{Olanzapine in Tourette syndrome}

Sir: Poor or partial response and sideeffects hamper the use of conventional neuroleptics in Tourette syndrome.

Since onset at age five, a 16-year-old girl has had several motor tics; vocalisation started aged 11 and coprolalia at 14. She has palilalia, forced touching and several compulsive-type behaviours. Her tics are severe enough for her to cause self-injury. Her diagnosis was confirmed at a major specialist centre for tic disorder, where in 1996 she scored 48 on the Yale Global Tic Severity Rating Scale.

From presentation three-and-a-half years ago, she has been on haloperidol, pimozide and risperidone. All were discontinued due to either poor control of her symptoms or side-effects. After informed consent all medication was withdrawn. The patient and her mother rated her tics at $10_{+}$ over a two-week drug-free period, on a scale of $0-10$. She was started on olanzapine $5 \mathrm{mg}$ daily, raised to $10 \mathrm{mg}$ daily after one week. Over nine weeks of trearment a partial control of the tic symptoms has been achieved, with the patient and parent rating fluctuating between 4 and 8 . Increased appetite lasted four weeks. Drowsiness improved when the medication was taken at night. A degree of tiredness, not interfering with daily activities, including school, continues.

I am not aware of any published reports of the use of olanzapine in Tourette disorder. The effects of the newer antipsychotics on dopaminergic, serotonergic and adrenergic systems, implicated in the pathophysiology of Tourette syndrome may suggest a useful role for these medications (Chappell et al, 1997). It would be at considerable theoretical interest if drugs with less potent action at dopaminergic sites were shown to be effective in diverse disorders considered to be associated with dopaminergic dysfunction at different brain sites.

Chappell, P. B., Scahill, L. D., Lockman, J. F. (1997) Future therapies of Tourette syndrome. Neurological Clinics of North Americo. 15. 429-450.

B. R. Bhadrinath Bethel Child and Family Centre, Mary Chapman House, Hotblack Road, Norwich NR2 4HN

\section{Liver transplantation for alcoholic liver disease}

Sir: Howard \& Fahy (1997) have helpfully described assessment before and after liver transplantation for alcoholic liver disease. A marker of regular excessive drinking which is rarely affected by liver disease is serum carbohydrate-deficient transferrin. It has been shown to detect relapse and is more sensitive and specific than gamma glutamyl transferase (Mitchell et al, 1997).

Howard, L. Fahy, T. (1997) Liver transplantation for alcoholic liver disease. British journol of Psychotry. 171. 497-500.

Mitchell, C., Simpson, D. \& Chick, J. (1997) Carbohydrate-deficient transferrin in detecting relapse in alcohol dependence. Drug and Alcohol Dependence. 48. $97-103$.

J. Chick Alcohol Problems Clinic, 35 Morningside Park, Edinburgh EHIO 5HD

\section{Attention deficit hyperactivity disorder in adults}

Sir: It is good to see how much emphasis has been given to developmental issues and their impact into adulthood in recent issues of the Journal. Toone \& van der Linden (1997) have given us a good resumé of attention deficit hyperactivity disorder (ADHD) in adults. I would like to clarify the following points which may be of interest to readers.

Pemoline has been withdrawn because of concerns about serious hepatic toxicity, which in some cases has proved fatal. There was discussion of methylphenidate and dexamphetamine as first-line drugs in treatment of $\mathrm{ADHD}$, but no mention of second-line drugs such as clonidine and tricyclics, which are useful in some circumstances (e.g. clonidine in Tourette syndrome).

Drug treatment is not the only management option. The efficacy of a psychosocial approach to the condition should not be overlooked. Child and adolescent psychiatrists would rarely use drugs as the only treatment. Other ways of approaching the difficulties which show promise include cognitive therapy to increase selfesteem and refine interpersonal skills, training in time management and selforganisation skills, self-control methods and vocational counselling. Many child and adolescent psychiatrists would try combinations of these as well as environmental manipulation before turning to drug therapy. We eagerly await the results of the Maryland collaborative multimodal trial for further clarification of this (Arnold et al, 1997). Further studies are needed to elucidate the application to adults.

Little emphasis was given to how difficult the diagnosis of ADHD can be. This is not just because of the substantial comorbidity with other mental illnesses, but also because of the other conditions that include attention and organisational deficits as features.

Lastly, the aetiology remains unclear, with research yielding inconsistent and conflicting results. There is little doubt that multiple aetiologies may lead to ADHD. A few environmental theories have been proposed (Willis \& Lovaas, 1977; Tallmadge \& Barkley, 1983) which, although not proven, present confounding issues. Negative parent-child interactions may cause hyperactivity, but are associated with its persistence. The greater the hyperactivity, the greater the negative reactions are likely to be. This may affect the disorder over time and confound diagnostic issues.

Arnold, L. E., Abikoff, H. B., Cantwell, D. P., et al (1997) National Institute of Mental Health Collaborative Multimodal Treatment study of Children with ADHD (the MTA). Design challenges and choices. Archives of General Psychiatry. 54, 865-870.

Tallmadge, 1. Barktey, R. A. (1983) The interactions of hyperactive and normal boys with their mothers and fathers. Journol of Abnormal Child Psychology. II. 565-579.

Toone, B. K. van der Linden, G. J. H. (1997) Attention deficit hyperactivity disorder of hyperkinetic disorder in adults. British journol of Psychrotry. 170. 489-491.

Wilis, T. J. Lovas, 1. (1977) A behavioural approach to treating hyperactive children. In Leorning Disobilities and Reloted Disorders (ed. J. B. Millichap). Pp. 119-140. Chicago, IL: Year Book Medical.

S. Cubbin, A. Leahy Child and Family Service, Wrekin Hospital, Holyhead Road, Wellington, Telford TFI 2ED 